Case Report

\title{
Ritodrine-Induced Agranulocytosis: A Case Report and Literature Review
}

\author{
Atsushi Daimon (D), Misa Nunode, Takumi Sano, Tomohito Tanaka, Daisuke Fujita, \\ and Masahide Ohmichi
}

Department of Obstetrics and Gynecology, Osaka Medical College, Osaka, Japan

Correspondence should be addressed to Atsushi Daimon; gyn146@osaka-med.ac.jp

Received 12 March 2020; Revised 29 July 2020; Accepted 3 August 2020; Published 8 August 2020

Academic Editor: Seung-Yup Ku

Copyright (C) 2020 Atsushi Daimon et al. This is an open access article distributed under the Creative Commons Attribution License, which permits unrestricted use, distribution, and reproduction in any medium, provided the original work is properly cited.

\begin{abstract}
Ritodrine hydrochloride is used for preterm labor, although serious side effects, including agranulocytosis, are reported. We report a case of ritodrine hydrochloride-induced agranulocytosis accompanied by bacteremia due to catheter infection. At 24 weeks of gestation, a female patient presented due to threatened premature labor and was administered continuous intravenous infusion of ritodrine hydrochloride. On day 36 after starting intravenous ritodrine hydrochloride, she was diagnosed with agranulocytosis. The white blood cell and granulocyte count nadirs were $1,660 / \mu l$ and $438 / \mu \mathrm{l}$. The cumulative dose of ritodrine hydrochloride was $2,610 \mathrm{mg}$. Ritodrine therapy was immediately stopped, and she was given an intravenous injection of antibiotics and granulocyte colony-stimulating factor. From her blood culture, methicillin-sensitive Staphylococcus aureus was detected. However, she started vaginal delivery two days after we stopped the ritodrine infusion. When using ritodrine hydrochloride, it is necessary to frequently check the white blood cell count, regardless of the total dose and treatment period.
\end{abstract}

\section{Introduction}

Ritodrine, a beta- 2 adrenergic agonist, is a widely used tocolytic agent for treating preterm uterine contractions. However, it has some maternal side effects, such as tachycardia, elevated liver enzymes, pulmonary edema, impaired glucose tolerance, finger shivering, and, rarely, rhabdomyolysis and agranulocytosis $[1,2]$.

We, herein, report a case of agranulocytosis due to continuous infusion therapy with ritodrine and summarize ritodrine-induced agranulocytosis.

\section{Case Presentation}

A 38-year-old woman (gravida 1, para 0) was admitted with complaints of uterine contractions at 24 weeks and 1 day of gestation. At admission, her white blood cell (WBC) count was $11,600 / \mu \mathrm{l}$, with $73.7 \%$ segmented neutrocytes. We started continuous intravenous ritodrine hydrochloride treatment at a dose of $50 \mu \mathrm{g} / \mathrm{min}$, and the dose was increased to $75 \mu \mathrm{g} / \mathrm{min}$ according to uterine contractions and the cervical length (Figure 1). Routine blood tests were performed once a week. On day 36 after the start of therapy, she developed a fever of $39^{\circ} \mathrm{C}$, and redness and swelling were found at the intravenous drip penetration point. We suspected an intravascular indwelling catheter infection, and blood tests and cultures were performed. Her WBC count was $1,660 / \mu \mathrm{l}$, with $26.4 \%$ segmented neutrocytes $(438 / \mu \mathrm{l})$, and the C-reactive protein (CRP) level was elevated to $3.15 \mathrm{mg} / \mathrm{dl}$ (Table 1). Drug-induced agranulocytosis by ritodrine was diagnosed. Ritodrine therapy (cumulative dose of 2,610 mg) was immediately stopped. We started an intravenous injection of an antibiotic (cefazolin (CEZ) $2 \mathrm{~g}$ /day) and intramuscular injection of $75 \mu \mathrm{g} /$ body of granulocyte colonystimulating factor (G-CSF). On day 37 after the start of therapy, gram-positive cocci suspicious for Staphylococci were detected in her blood culture. Considering the possibility of methicillin-resistant Staphylococcus aureus (MRSA), the antibiotic was changed to vancomycin hydrochloride ( $2 \mathrm{~g} /$ day). On day 38 after the start of therapy, the patient 


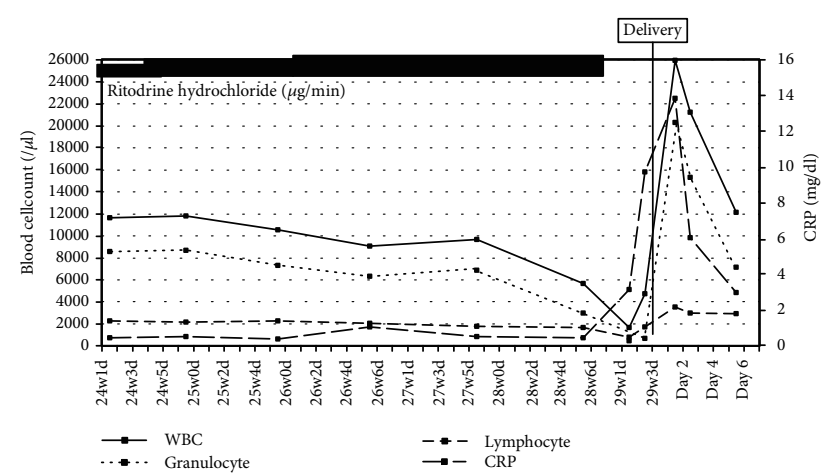

Figure 1: Changes in the WBC, granulocyte, lymphocyte, and CRP values from 24 weeks of gestation to 6 days postpartum.

TABle 1: Blood examination findings at the onset of agranulocytosis.

\begin{tabular}{lccc}
\hline WBC $(/ \mu \mathrm{l})$ & 1,660 & TP $(\mathrm{g} / \mathrm{dl})$ & 6.3 \\
RBC $\left(10^{3} / \mu \mathrm{l}\right)$ & 3,760 & Alb $(\mathrm{g} / \mathrm{dl})$ & 3.2 \\
$\mathrm{Hb}(\mathrm{g} / \mathrm{dl})$ & 11.9 & T-Bil $(\mathrm{mg} / \mathrm{dl})$ & 0.3 \\
Plt $\left(10^{3} / \mu \mathrm{l}\right)$ & 368 & AST $(\mathrm{U} / \mathrm{L})$ & 22 \\
Granulocyte $(/ \mu \mathrm{l})$ & 438 & ALT $(\mathrm{U} / \mathrm{L})$ & 25 \\
Lymphocyte $(/ \mu \mathrm{l})$ & 774 & BUN $(\mathrm{mg} / \mathrm{dl})$ & 5 \\
CRP $(\mathrm{mg} / \mathrm{dl})$ & 3.15 & Cre $(\mathrm{mg} / \mathrm{dl})$ & 0.44 \\
\hline
\end{tabular}

developed frequent uterine contractions and started magnesium sulfate $(1 \mathrm{~g} / \mathrm{h})$ administration. However, her uterine contractions strengthened, resulting in the vaginal delivery of a 1,288 g male infant with an Apgar score of 7 at $1 \mathrm{~min}$ and 8 at $5 \mathrm{~min}$. On day 2 after delivery, her blood culture result revealed methicillin-sensitive Staphylococcus aureus (MSSA); therefore, her antibiotics were switched to CEZ ( $3 \mathrm{~g} /$ day). On day 5 after delivery, her WBC count rose to $12,120 / \mu \mathrm{l}$, with $59.0 \%$ segmented neutrocytes $(7,151 / \mu \mathrm{l})$, and her CRP decreased to $2.99 \mathrm{mg} / \mathrm{dl}$. She was discharged without infectious complications. Her infant was placed in the neonatal intensive care unit, had an uncomplicated neonatal course, and was discharged without any morbidity on day 71 after delivery.

\section{Discussion}

Ritodrine hydrochloride is the most frequently used and most effective tocolytic agent for patients with preterm labor in Japan. The side effects of ritodrine hydrochloride include tachycardia, elevated liver enzymes, pulmonary edema, impaired glucose tolerance, finger shivering, and, rarely, rhabdomyolysis and agranulocytosis. Ritodrine hydrochloride-induced agranulocytosis was first reported in 1986 [1]. We searched for case reports or clinical studies on ritodrine-induced agranulocytosis in the PubMed database and the database of the Japan Medical Abstracts Society (1986-2017) and found 40 studies and 47 case reports of the disorder, including our own; 44 cases were reported in Japan, and 1 case each was reported in the USA, China, and Taiwan. The mean duration of ritodrine therapy was 30.3
TABLE 2: The 47 cases found in our literature review of ritodrine hydrochloride-induced agranulocytosis in pregnancy.

\begin{tabular}{|c|c|}
\hline Mean maternal age (range) (years) & $29.6(21-40)$ \\
\hline Multiparous (\%) & $15(31.9)$ \\
\hline Multiple pregnancy (\%) & $14(29.8)$ \\
\hline \multicolumn{2}{|c|}{ Ritodrine therapy } \\
\hline Mean duration (range) (days) & $30.3(21-69)$ \\
\hline Mean cumulative dose (range) (mg) & $6,642(2,000-17,700)$ \\
\hline \multicolumn{2}{|c|}{ Labor date at onset of agranulocytosis } \\
\hline WBC (range) $(/ \mu \mathrm{l})$ & $1,864(790-3,500)$ \\
\hline Granulocyte (range) $(/ \mu \mathrm{l})$ & $216(0-1,925)$ \\
\hline \multicolumn{2}{|c|}{ Concomitant drug } \\
\hline Magnesium sulfate (\%) & $17(36.2)$ \\
\hline Indomethacin (\%) & $5(10.6)$ \\
\hline Infection signs $(\%)$ & $21(44.7)$ \\
\hline Antibacterial (\%) & $31(66.0)$ \\
\hline G-CSF (\%) & $35(74.5)$ \\
\hline Preterm birth (\%) & $25(53.2)$ \\
\hline
\end{tabular}

days (range, 21-69 days), and the mean cumulative ritodrine dose based on 38 cases for which the necessary data were reported was 6,642 $\mathrm{mg}$ (range, 2,000-17,700 $\mathrm{mg}$ ) (Table 2). This result was similar to that of a previous report [3]. All patients stopped receiving ritodrine after being diagnosed with ritodrine-induced agranulocytosis. Thirty-five patients (74.5\%) were treated with G-CSF, and 31 patients (66.0\%) were administered antibiotics. One patient was diagnosed with a pulmonary Aspergillus infection, which was treated with oral itraconazole [4]. All patients were discharged without any complications. The preterm birth rate was $53.2 \%$ of the patients who developed ritodrine-induced agranulocytosis. In previous reports, there were no cases with positive blood cultures [5], and this case was the first in which causative bacteria (MSSA) were detected in the blood culture test. As inflammatory cytokines, such as IL- 6 and TNF- $\alpha$, are known to be increased before and after parturition in cases of premature birth [6], the bacteremia-induced elevation of inflammatory cytokines may have caused preterm birth in our patient.

As no specific symptoms of agranulocytosis have been described, it is detected in many cases by regular blood tests. When using ritodrine hydrochloride, physicians should regularly check the WBC count, regardless of the total dose and treatment period. The lower normal cutoff values of WBCs and granulocytes during pregnancy are $6,000 / \mu \mathrm{l}$ and $3,800 / \mu \mathrm{l}$, respectively [7]. When values drop below these numbers, the onset of agranulocytosis should be suspected and more frequent blood tests should be considered.

\section{Abbreviation}

WBC: White blood count

CRP: C-reactive protein

CEZ: Cefazolin

G-CSF: Granulocyte colony-stimulating factor 
MRSA: Methicillin-resistant Staphylococcus aureus

MSSA: Methicillin-sensitive Staphylococcus aureus.

\section{Consent}

Written informed consent was obtained from the patient for the publication of this case report and the accompanying images.

\section{Conflicts of Interest}

The authors declare no conflict of interests in association with the present study.

\section{Authors' Contributions}

$\mathrm{AD}$ treated the patient and was responsible for collecting and interpretation of data and drafting of the manuscript. DF and MO are the chiefs of our department and have a responsibility of all patients' outcome and paper publication. All authors reviewed and contributed to the final version of this case report. All authors read and approved the final manuscript. The authors alone are responsible for the content and writing of the paper.

\section{Acknowledgments}

We would like to thank Editage (http://www.editage.com) for English language editing.

\section{References}

[1] R. Wang-Cheng and B. J. Davidson, "Ritodrine-induced neutropenia," American Journal of Obstetrics and Gynecology, vol. 154, no. 4, pp. 924-925, 1986.

[2] Y. Matsuda, Y. Nagayoshi, and N. Kirihara, "Rhabdomyolysis during prolonged intravenous tocolytic therapy," Journal of Perinatal Medicine, vol. 30, no. 6, pp. 514-516, 2002.

[3] L. Zhang, X. Liu, and J. Li, "Ritodrine-induced agranulocytosis in pregnancy," Journal of Obstetrics and Gynaecology, vol. 34, no. 6, pp. 533-538, 2014.

[4] F. Aoki, Y. Sando, S. Tajima et al., "Invasive pulmonary aspergillosis in a puerperant with drug-induced agranulocytosis," Internal Medicine, vol. 40, no. 11, pp. 1128-1131, 2001.

[5] R. Yasuda, Y. Makino, Y. Matsuda, Y. Kawamichi, and H. Matsui, "Agranulocytosis associated with intravenous ritodrine hydrochloride therapy: two case reports by different mechanisms," Journal of Obstetrics and Gynaecology Research, vol. 38, no. 3, pp. 574-577, 2012.

[6] R. Romero, B. H. Yoon, M. Mazor et al., "The diagnostic and prognostic value of amniotic fluid white blood cell count, glucose, interleukin-6, and Gram stain in patients with preterm labor and intact membranes," American Journal of Obstetrics and Gynecology, vol. 169, no. 4, pp. 805-816, 1993.

[7] F. Cunningham, K. Leveno, S. Bloom, C. Y. Spong, and J. Dashe, Williams Obstetrics, McGraw-Hill education, USA, 24th edition, 2014. 